\title{
Intraoral reinsertion after extracorporeal fixation in condylar fracture
}

\author{
Soung Min Kim ${ }^{1,2}$ \\ ${ }^{\prime}$ Oral and Maxillofacial Microvascular Reconstruction LAB, Brong Ahafo Regional Hospital, Sunyani, Ghana, \\ ${ }^{2}$ Department of Oral and Maxillofacial Surgery, Dental Research Institute, School of Dentistry, Seoul National University, Seoul, Korea
}

Abstract (J Korean Assoc Oral Maxillofac Surg 2021;47:476-479)

For treatment of mandibular condyle fracture, this article introduces the surgical protocol of intraoral reinsertion after extracorporeal fixation. This efficient, anatomically acceptable, extraoral scar-free, and relatively uncomplicated approach for condylar fracture can be compared with conventional extraoral fixation through various approaches. Clinical step-by-step procedures with a scientific basis were described in this technical strategy note.

Key words: Mandibular condyle fracture, Intraoral reinsertion, Extracorporeal fixation, Intraoral reinsertion after extracorporeal fixation [paper submitted 2020. 11. 4 / revised 2020. 12. 8 / accepted 2020. 12. 10]

\section{Introduction}

Previous studies have compared open and closed reduction for treatment of mandibular condyle fracture (MCF) through an assessment of functional outcomes, such as maximum mouth opening, stable occlusion, temporomandibular joint (TMJ) pain, facial symmetry, and total mandibular activity ${ }^{1-3}$. For patients older than 16 years, many different surgical approaches for MCF have been recommended, depending on the surgeon's skill and the patient's acceptance of possible complications ${ }^{4,5}$.

Over the last 15 years, we have performed intraoral reinsertion after extracorporeal fixation (IREF) on more than 120 consecutive patients with MCF. In this technical strategy note, we described our detailed step-by-step procedures for IREF. We also compared conventional surgical approaches to MCF with IREF with schematic drawings, and we described essential considerations to prevent complications such as condylar head absorption, mouth opening limitation with de-

\footnotetext{
Soung Min Kim

Department of Oral and Maxillofacial Surgery, Dental Research Institute, School of Dentistry, Seoul National University, 101 Daehak-ro, Jongno-gu, Seoul 03080, Korea

TEL: +82-2-2072-0213

E-mail:smin5@snu.ac.kr

ORCID: https://orcid.org/0000-0002-6916-0489
}

(c) This is an open-access article distributed under the terms of the Creative Commons Attribution Non-Commercial License (http://creativecommons.org/ licenses/by-nc/4.0/), which permits unrestricted non-commercial use, distribution, and reproduction in any medium, provided the original work is properly cited.

Copyright (C) 2021 The Korean Association of Oral and Maxillofacial Surgeons. viation, and postoperative pain.

\section{Technical Note}

Acceptable results of IREF for MCF have been described in clinical retrospective experiences and reports ${ }^{6,7}$. Under strict indications and guidelines, IREF can be a good option to achieve successful outcomes. Indications for open reduction of MCF have been known as several factors including patient age greater than 16 years, condylar fracture at the condylar neck or above, severely displaced or dislocated condylar fracture, and malocclusion due to loss of posterior condylar height.

Intraoral vestibular and buccal gingival incision is needed to expose the mandibular oblique ridge and ascending ramus by dissection of the angle and internal ramus together. After identification of the fracture lines above the sigmoid notch, coronoidectomy could be considered for the better visualization. If the fractured condylar segment is visible and the sagittal split proximal portion can be easily detached from the surrounding masticatory muscles, the coronoid process could be preserved without resection. In most cases, a small triangular bony edge of the coronoid process can be removed for better visualization and safe repositioning of the extracorporeal fixated proximal segment.

Sagittal split osteotomy with a reciprocating saw, chisel, and mallet can be performed in the same way as for orthognathic surgery. The proximal segment is removed extracor- 
poreally and kept in a warm saline bath in a metal bowl to maintain body temperature. After removal of the proximal segment, the remaining fractured condylar portion should be carefully dissected and removed as quickly as possible. Likewise, extracorporeal removal of the fractured segment should be carried out quickly and with as little trauma as possible. A retraction elevator or instruments should be readied by the surgical assistants during extracorporeal fixation by the main operator. This procedure is especially important to maintain the position of the condylar head for reinsertion to the original temporal fossa position. The removed fractured segment can be relocated to the proximal segment anatomically and should be fixed with miniplates and/or microplates as quickly as possible.(Fig. 1. A-1. C) Warm saline irrigation is recommended for the drilling procedure to maintain body temperature.

On the basis of our experiences treating more than 147 cases of MCF in 120 patients, we suggest that procedure time for removal and reinsertion of the fixated condylar segment to its original TMJ space should not exceed 30 minutes. Limiting this operative time helps to prevent postoperative complications, such as bone necrosis or cellular damage. After reinsertion, intermaxillary fixation through anchored screws or arch bars should be performed after confirmation of the original position of the sagittal split osteotomy line. This segment can be fixed with the same type of miniplate used in the orthognathic surgical procedure.(Fig. 1. D) Stable occlusion without lateral interference or deviation should be confirmed after boxing wire removal, and condylar translation with smooth rotation is also recommended.

The final surgical procedure involves insertion of Hemovac, an intraoral vacuum containing drain, along the inferior border of the mandible until the coronoid space adjacent to the fixated condylar head.(Fig. 2. C) This drain can also be anchored through the intraoral mucosa to avoid an unnecessary extraoral wound. Immediately after the procedure, the patient must be taught exercises for opening and closing the mouth to maintain occlusion of the upper and lower teeth.
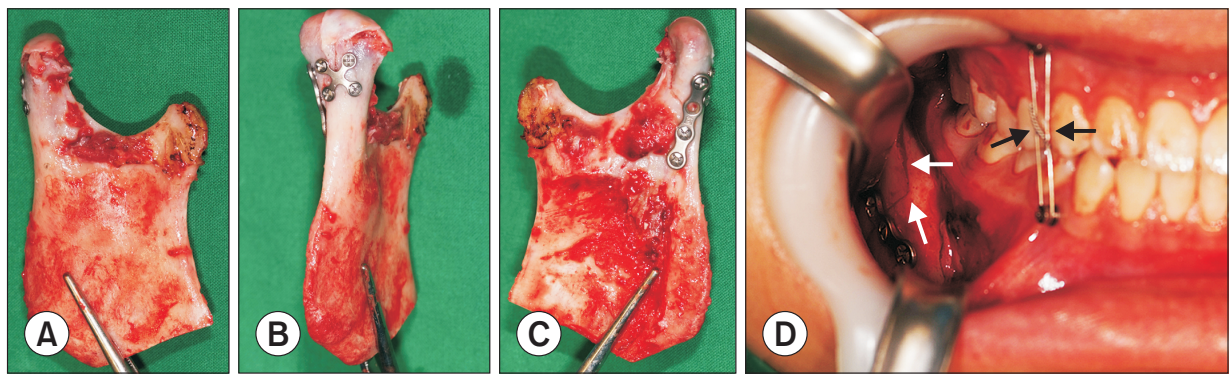

Fig. 1. A-C. Clinical photos of extracorporeal fixation and reduction in condylar head fracture showing lateral (A), posterior (B), and medial (C) views after fixation of the fractured segments. D. Reinsertion through an intraoral approach and re-fixation to the original ostectomy site (white arrows) under intramaxillary fixation (black arrows).

Soung Min Kim: Intraoral reinsertion after extracorporeal fixation in condylar fracture. J Korean Assoc Oral Maxillofac Surg 2021

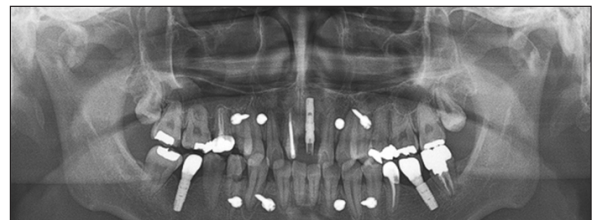

(A)

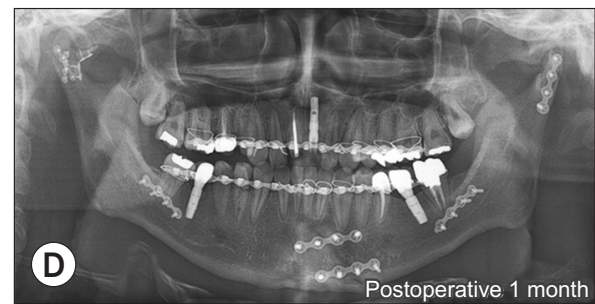

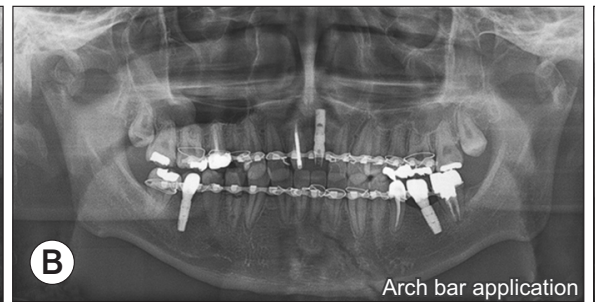

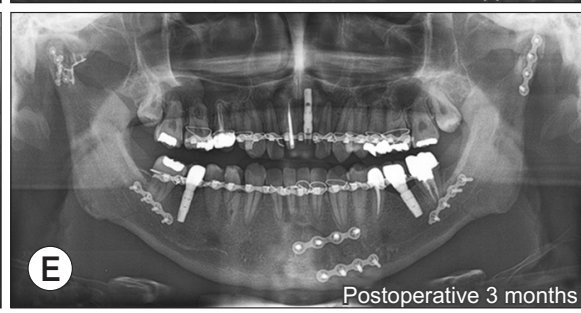

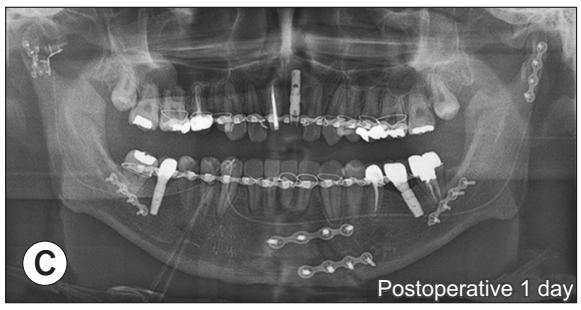

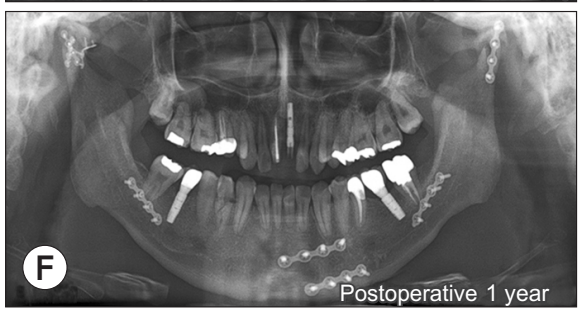

Fig. 2. Radiograms of bilateral condylar head fracture. Preoperative (A), after arch bar application with intermaxillary fixation (B), postoperative day $1(C)$, postoperative 1 month (D), postoperative 3 months $(E)$, and postoperative 1 year (F).

Soung Min Kim: Intraoral reinsertion after extracorporeal fixation in condylar fracture. J Korean Assoc Oral Maxillofac Surg 2021 
Sometimes, a rubber chain between the upper and lower anchorage screws or the arch bar can help to guide stable occlusion and rapid muscular reattachment to the reinserted bony segment.

Frequent buccal cheek massage with both hands can help reduce swelling and hematoma, and continuous cheek massage could facilitate Hemovac drainage until 2 to 5 days postoperatively. The patient can be discharged after drain removal within 5 to 7 days. The postoperative exercises should be performed for at least 4 weeks. We could achieve a successful final outcome as no pain or discomfort, stable occlusion without deviation, mouth opening greater than $35 \mathrm{~mm}$, and symmetrical facial contour during 1-year follow-up check. (Fig. 2)

\section{Discussion}

Suggested surgical technical note is an intraoral approach basically; thus, we invoked the terminology of IREF rather than extraoral fixation. The 'extracorporeal' terminology has been used in cardiac or respiratory medicine, such as extracorporeal life support, extracorporeal membrane oxygenation, extracorporeal life or lung support, extracorporeal cardiopulmonary resuscitation, and extracorporeal shock wave therapy. For salvage of hypoxemic status in patients with complicated chest trauma, extracorporeal membranous oxygenation to achieve respiratory oxygenation has been widely used in the medical field'. Thus, our use of 'extracorporeal fixation' can be interpreted as 'extraoral direct fixation of fractured segments' in patients with $\mathrm{MCF}^{8-11}$.

Various surgical approaches have been reported to treat MCF, and the advantages of intraoral reduction have been described. However, controversies have been continuing to surround the surgical treatment of condylar fracture ${ }^{12,13}$. In the position paper from the IBRA Symposium on Surgery of the Head, Condylar Fracture Osteosynthesis, Marseille, France $2012^{14}$, the extraoral approach was subdivided into subman- dibular $^{15}$, retromandibular, preauricular, and transparotid ${ }^{16}$ approaches. Authors have classified the extraoral approach as direct reduction with fixation via a submandibular or endaural approach, extracorporeal fixation with vertical ramus osteotomy, intraoral direct reduction and fixation with an angled driver or transbuccal set with endoscopic visualization ${ }^{7}$. Fig. 3 summarized various approaches to MCF including our suggested IREF.

From our experiences, the clinical and radiographic findings suggest that IREF could be a better choice than other recommended techniques because it leads to anatomically accurate reduction with a low risk of complications. The greatest advantages of IREF are that the intraoral approach prevents facial scars and facilitates anatomical and accurate repositioning through direct visualization. However, complications of IREF can occur because the procedure involves non-vascularized bone graft to the inside of the TMJ. Thus, only the surrounding blood supply from adjacent muscles and fascia should be recirculated to the grafted segment. During this process, a short ischemic time for the proximal segment and appropriate functioning of the Hemovac drain are the most important factors for successful outcomes. An intraoral Hemovac drain should be maintained for several days during the patient's active mouth opening exercises. If the Hemovac is malfunctioned or removed too quickly, the whole proximal segment or the fractured segment may become necrotic ${ }^{17}$.

This study reported on the use of IREF for MCF with an intraoral approach that included sagittal split osteotomy, direct fixation with or without the use of a rectangular driver, and intraoral Hemovac insertion. In all of our cases, these advantages prevented an unattractive extraoral scar. The IREF procedure also involved large bony contact to the detached muscle fibers through intraoral sagittal split osteotomy, compared to a small bony segment in the case of extraoral vertical ramus osteotomy, which could have a narrow bony contact surface that could be addressed with another ostectomized bony margin and surrounding muscle fibers ${ }^{17}$.

\section{A}

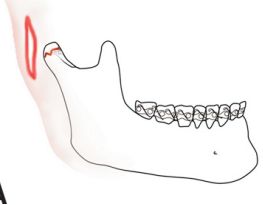

B

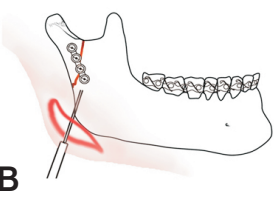

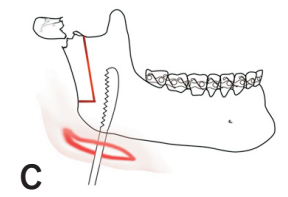
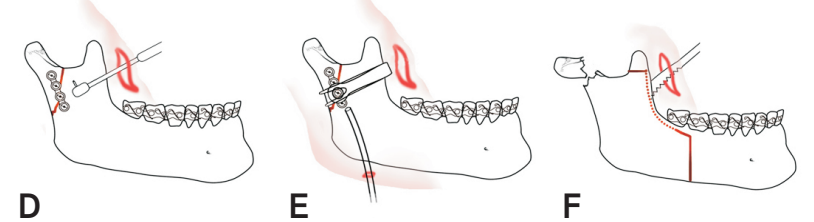

Fig. 3. Schematic drawings of representative surgical approaches in mandibular condylar fracture. Direct reduction and fixation via the (A) endaural or (B) submandibular approach, (C) extracorporeal fixation with vertical ramus osteotomy, (D) intraoral direct reduction and fixation with an angled driver or (E) transbuccal fixation with or without endoscopic visualization, and (F) intraoral reinsertion after extracorporeal fixation of the fractured fragment.

Soung Min Kim: Intraoral reinsertion after extracorporeal fixation in condylar fracture. J Korean Assoc Oral Maxillofac Surg 2021 
In conclusion, this technical note showed that IREF is a reliable treatment option for condylar fracture management. If clinicians apply this minimally invasive method with a clean intraoral sagittal osteotomy, fast and accurate location of the fractured fragment and extracorporeal reduction, anatomical repositioning to the original condylar position, and active mouth opening exercises with extraoral muscular massage, the outcomes will be successful for patients with MCF.

\section{Author's Contributions}

S.M.K. participated in study design, data collection, and wrote the manuscript.

\section{Acknowledgements}

This research was supported by Basic Science Research Program through the National Research Foundation of Korea funded by the Ministry of Education (2017R1D1A1B04029339).

\section{Ethics Approval and Consent to Participate}

This article was approved by the Institutional Review Board of Seoul National University (S-D20170029). Informed consent was obtained from the individual patient included in this study.

\section{Conflict of Interest}

No potential conflict of interest relevant to this article was reported.

\section{References}

1. Yao S, Zhou J, Li Z. Contrast analysis of open reduction and internal fixation and non-surgical treatment of condylar fracture: a meta-analysis. J Craniofac Surg 2014;25:2077-80. https://doi. org/10.1097/SCS.0000000000001010

2. Hackenberg B, Lee C, Caterson EJ. Management of subcondylar mandible fractures in the adult patient. J Craniofac Surg 2014;25: 166-71. https://doi.org/10.1097/SCS.0000000000000498

3. Oruç M, Işik VM, Kankaya Y, Gürsoy K, Sungur N, Aslan G, et al. Analysis of fractured mandible over two decades. J Craniofac Surg 2016;27:1457-61. https://doi.org/10.1097/SCS.0000000000002737

4. Shi J, Jiao F, Xu B, Yu H. Transparotid approach in the treatment of intracapsular condylar fracture. J Craniofac Surg 2015;26:495-7. https://doi.org/10.1097/SCS.0000000000001524
5. Hong SO, Ohe JY, Lee DW. Salvage of the condylar fracture: complication management of mandibular angle ostectomy. J Craniofac Surg 2014;25:e582-4. https://doi.org/10.1097/ SCS.0000000000001028

6. Kim JH, Kim SM, Kwon GJ, Park YW. Clinical review of various surgical approaches in the treatment of mandibular condyle fracture. J Korean Assoc Maxillofac Plast Reconstr Surg 2008;30:7282.

7. Kim SM, Kim JH. Commentary to "A follow-up study on extracorporeal fixation of condylar fractures using vertical ramus osteotomy”. J Korean Assoc Oral Maxillofac Surg 2016;42:236-7. https:// doi.org/10.5125/jkaoms.2016.42.4.236

8. Park SY, Im JH, Yoon SH, Lee DK. A follow-up study on extracorporeal fixation of condylar fractures using vertical ramus osteotomy. J Korean Assoc Oral Maxillofac Surg 2014;40:76-82. https:// doi.org/10.5125/jkaoms.2014.40.2.76

9. Park JM, Jang YW, Kim SG, Park YW, Rotaru H, Baciut G, et al. Comparative study of the prognosis of an extracorporeal reduction and a closed treatment in mandibular condyle head and/or neck fractures. J Oral Maxillofac Surg 2010;68:2986-93. https://doi. org/10.1016/j.joms.2010.02.034

10. Kannadasan K, Shenoy KV, Kengagsubbiah S, V S, Priya $\mathrm{V}$. Extra corporeal fixation of fractured mandibular condyle. J Clin Diagn Res 2014;8:ZD41-3. https://doi.org/10.7860/ JCDR/2014/10484.4914

11. Gali R, Devireddy SK, Venkata KK, Kanubaddy SR, Nemaly C, Dasari M. Preauricular transmasseteric anteroparotid approach for extracorporeal fixation of mandibular condyle fractures. Indian J Plast Surg 2016;49:59-65. https://doi.org/10.4103/09700358.182254

12. Fayazi S, Bayat M, Bayat-Movahed S, Sadr-Eshkevari P, Rashad A. Long-term outcome assessment of closed treatment of mandibular fractures. J Craniofac Surg 2013;24:735-9. https://doi.org/10.1097/ SCS.0b013e3182801373

13. Vajgel A, de Santana Santos T, Camargo IB, Moraes de Oliveira D, Filho JR, de Holanda Vasconcellos RJ. Management of subcondylar fracture by intraoral approach. J Craniofac Surg 2013;24:587-8. https://doi.org/10.1097/SCS.0b013e31827c86c4

14. Neff A, Chossegros C, Blanc JL, Champsaur P, Cheynet F, Devauchelle B, et al.; International Bone Research Association. Position paper from the IBRA Symposium on Surgery of the Head-the 2nd International Symposium for Condylar Fracture Osteosynthesis, Marseille, France 2012. J Craniomaxillofac Surg 2014;42: 1234-49. https://doi.org/10.1016/j.jcms.2014.03.005

15. Conci RA, Tomazi FH Jr, Kalaoun R, Fritscher GG, de Oliveira GR, Heitz C. Modified submandibular access for open reduction and internal rigid fixation in condylar fractures. J Craniofac Surg 2015;26:232-4. https://doi.org/10.1097/SCS.0000000000001099

16. Pilanci Ö, Basaran K, Ceran F, Kuvat SV. Functional outcomes of preauricular underparotid retrograde approach for mandibular condyle fractures. J Craniofac Surg 2014;25:1078-81. https://doi. org/10.1097/SCS.0000000000000514

17. Hwang K, Park JH, Lee HJ. Miniplate fixation of high condylar fracture and postoperative exercise regimen. J Craniofac Surg 2005;16:113-6. https://doi.org/10.1097/00001665-20050100000021

How to cite this article: Kim SM. Intraoral reinsertion after extracorporeal fixation in condylar fracture. J Korean Assoc Oral Maxillofac Surg 2021;47:476-479. https://doi.org/10.5125/ jkaoms.2021.47.6.476 